\title{
Role of ROS in A $\beta 42$ mediated cell surface P-selectin expression and actin polymerization
} \author{
Zhaksybay Zhumadilov ${ }^{1}$ \\ From Molecular Neurodegeneration: Basic biology and disease pathways \\ Cannes, France. 10-12 September 2013
}

Andrey Tsoy ${ }^{1,2^{*}}$, Sholpan Askarova ${ }^{1}$, Tamara Shalakhmetova², Bauyrzhan Umbayev' ${ }^{1}$, Shalkar Adambekov',

\section{Background}

Blood Brain barrier (BBB) dysfunction plays an important role in the onset and progression of Alzheimer's disease (AD). In the AD brains an increased deposition of $A \beta$ in the cerebral vasculature has been found to correlate with increased transmigration of blood-born inflammatory cells and neurovascular inflammation. Transmigration of leukocytes into brain parenchyma is a sequential process starting with primary capture to the endothelium and rolling adhesion mediated by tethering on selectins and selectin ligands. P-selectin is a type I transmembrane cell adhesion molecule which is stored in cytoplasmic Weibel-Palade bodies (WPb) and can be mobilized on the endothelial cell surface within minutes upon exposure to different proinflammatory agents; then it's rapidly cleared through endocytosis in $30 \mathrm{~min}$. It has become evident that $A \beta$ activates cerebral endothelial cells (CECs) and induces mobilization of P-selectin to the cell surface. However, expression mechanisms of this receptor on the surface of brain endothelial cells under administration with A $\beta 42$ remain unclear. Since P-selectin is stored in $\mathrm{WPb}$, and there is an evidence of active role of ROS (reactive oxygen species) and actin filaments in the different stages of $\mathrm{WPb}$ exocytosis, in this study we examined the dynamic of $\mathrm{P}$ - selectin expression on the endothelial cell surface activated by $\mathrm{A} \beta 42$ in relation to ROS and actin polymerization.

\section{Materials and methods}

In this study we used immortalized CECs (bEnd3) as following: control; cells incubated with $A \beta 42$ for 10,30 and $60 \mathrm{~min}$; cells incubated with $30 \mathrm{mM}$ of antioxidant $\mathrm{N}$-acetylcysteine (NAC) for $1 \mathrm{hr}$; cells pretreated with
NAC followed by A $\beta 42$ exposure. Fluorescent microscopy of anti-P-selectin, dihydroethidium (DHE), and Oregon green phalloidin was used to quantify the surface P-selectin expression, ROS production, and actin polymerization.

\section{Results}

We have observed that $A \beta 42$ promoted ROS production up to $34.5 \%, 61 \%, 83 \%$ and increased P-selectin fluorescence up to $28 \%, 46 \%, 54 \%$ after $10 \mathrm{~min}, 30 \mathrm{~min}$ and $60 \mathrm{~min}$ of treatment respectively. In contrast, pre incubation of cells with NAC prevented the superoxide production and attenuated $A \beta 42$ induced $\mathrm{P}$-selectin activation. At the same time, NAC alone significantly reduced DHE fluorescence, but did not affect expression of the adhesion receptor. QIM data also demonstrated that $A \beta 42$ promoted actin polymerization in cells, while pretreatment with NAC was able to suppress $A \beta$-induced actin polymerization and cytoskeletal reorganization in bEND3 cells.

\section{Conclusions}

The results of our study have indicated that $A \beta 42$ induces expression of P-selectin on the surface of bEnd 3 cells and promotes actin polymerization in a time dependent manner, and all these events correlate with ROS generation. The rapid, posttranslational cell signaling response, mediated by ROS, may well represent an important physiological trigger of the micro vascular inflammatory response in $\mathrm{AD}$ and requires further investigations.

\footnotetext{
Authors' details

${ }^{1}$ Center for life sciences, Nazarbaev University, Astana, Kazakhstan. ${ }^{2}$ Department of Biodiversity and Bioresources, Al-Farabi Kazakh National University, Almaty, Kazakhstan.
} 

and take full advantage of:

- Convenient online submission

- Thorough peer review

- No space constraints or color figure charges

- Immediate publication on acceptance

- Inclusion in PubMed, CAS, Scopus and Google Scholar

- Research which is freely available for redistribution 